\title{
The development of speech activity in students
}

\author{
Yunusova Diyora Aminovna ${ }^{1}$, Fayzullayev Farxod Ubaydullayevich ${ }^{2}$, Radjabov Jamol \\ Tog'aymurodovich ${ }^{3}$ \\ ${ }^{1,2,3}$ Samarkand Institute of Veterinary Medicine, Head of the "Uzbek and foreign languages" \\ department \\ Email: yunusova.diyora@yandex.com,rvarim@mail.ru,Jamol-1976@mail.ru
}

\begin{abstract}
This article issues on the problem of developing oral activity of students. The authors noted that such obligatory subjects as English language for bachelor course and professional foreign language for master course occupy a special place in modern higher education. These subjects are aimed to make the educational process not only effective, but also engaging for students and to make them the main characters of this process. The exercises are effective mostly due to the raise of motivation, interest to the subjects, which are important part of educational process.
\end{abstract}

Keywords: motivated, saying, lexical meanings, self-control, situation, active, purposeful, expressions, factors, relationship.

\section{INTRODUCTION}

Teaching Russian in the context of National-Russian bilingualism is traditionally viewed as a process that should help the learner master the basics of language knowledge and speech skills. Modern young people have the right to listen to music on the phone by phone, instead of which I invite them to listen to audio materials in Russian, which will further help them in the development of speech.

Speech activity is speaking, listening, reading, writing. The speaker and the writer invest a certain meaning; the listener and the reader extract their meaning from someone else's statement into their statements. In speech communication, a holistic act of speech is combined in two forms (speaking-listening and writing-reading) speech as a way of transmitting thought through language, language as a system of signs (sounds) denoting reality.

Oral speech is a motivated and situationally conditioned process. The situation creates a motive of conversation, the need for something and a request, a question, an answer, a statement and objections, misunderstanding and explanation, these and many other similar relations between motive and speech are determined by the actual situation. If you know the rules of the language, you will correctly build and understand simple sentences. To construct and understand complex statements, it is important to be able to connect and isolate semantic parts, to single out every thought of every particular judgment, which together reveal the main idea of the entire text.

\section{THE DEVELOPMENT OF SPEECH ACTIVITY IN STUDENTS}

During the statement, you select the words to be said, and keep in your memory what has already been said. For example, in a sentence I read a book telling about communication problems, I read the word, prepares the use of the word book in the accusative case which must be kept in memory, since the forms of the subsequent words depend on it.

The same happens with the text as a whole. You remember the beginning of the text because it is preserved in the inner speech where the words are replaced by inner images. However, you can express the meaning of a statement not only with the help of lexical meanings and their combinations, but also with intonation, which logically divides the expressed thought and makes speech emotionally turned to the interlocutor(Çağlayan, Şak, Karymshakov, Çaglayan, \& Sak, 2012; Festel, Gunter (Swiss Federal Institute of Technology, Department of Management, Technology and Economics / Technical University Berlin, Faculty of Economics and Management, Berlin, Nardo, Mikko (Swiss Federal Institute of Technology, Department of Management, \& Simmen, Timo (Swiss Federal Institute of Technology, Department of Management, 2014; Willson, 2011). So, the next kind of speech activity is listening. Like all types of speech activity, listening is of particular importance. 


\section{THEORETICAL BACKGROUND}

Perceiving the beginning of the thought, try to predict what will be said next and if your hypothesis is not correct, put forward a new one. Try to keep in your memory the beginning of the statement differently, having listened to the end of it, you will not be able to understand either the content or the meaning of the statement. Therefore, in the course of the hearing, replace the detailed statements with their convoluted equivalents, the key words with visual images with synonymous structures, schemes and words. To develop the skills of self-control and self-correction without which speech activity is impossible, listen several times to the recorded text and then retell your text. Correct your mistakes, find more accurate words to express your thoughts.

To develop the skills of self-control and self-correction without which speech activity is impossible, listen several times to the recorded text and then retell your text. Correct your mistakes, find more accurate words to express your thoughts.

Speech activity is one of the types of human activity understood by methodologists as "active, purposeful, mediated by the language system and the process of sending and receiving a message due to the communication situation [4, p. 17].

Speaking is a type of speech activity that is realized when there is a need in the speaker's mind for speech influence on the interlocutor. Various factors affect the speaking process, including: the purpose for which the speech act is performed; topic of communication; time and place of communication; relations between interlocutors (neutral, formal, friendly, advice, agreement); social and communicative role of partners (student and teacher, boss and subordinate, fellow students) [4, p. 279].

The work on teaching oral speech is based on the fact that real communication can be carried out in the form of dialogue and monologue. Dialogue (from the Greek "conversation, conversation of two") is a chain or a series of statements, when the participants in the conversation alternately act as the speaker and as the listener.

\section{LITERATURE REVIEW}

According to Russian researchers L.S. Kryuchkova, N.V. Moschinskaya, teaching speaking includes three components: 1) the introduction of language material into the memory of students; 2) development of skills of abilities to operate with this material; 3 ) the development of skills in the use of speech for real communication purposes [4, p. 280-282].

To productive types of speech activity include speaking and writing, to receptive - listening and reading. Speaking and writing play an active role in the process of communication, they are aimed at generating speech, therefore they are referred to as productive types of speech activity. Reading is a receptive type of speech activity, since It relies on the perception of graphic language signs. Reading is not only perception, but also the process of extracting information. The value of reading in a person's life is extremely great; it is through reading that we get a large amount of information necessary for us. Recently, the ability to read a foreign language is considered important for a literate person. Reading develops memory, improves speech. In addition, students through reading get acquainted with the countries of the language being studied(Journal \& Journal, 1995).

The German methodologist G. Pifo rightly remarked that there is hardly a person who denies the great importance of situationality for learning foreign language. The situation is a stimulus to speech and a set of events, relationships. The most common understanding of a situation is to understand it as a combination of the circumstances of reality, the background against which certain events unfold, actions, and these circumstances should serve as an incentive for speech action. Based on this, methodologists recommend using visibility to create situations.

In addition, as the practice of teaching shows, as a result of the exercise system, trainees acquire the communicative ability to manage dialogic communication, which contributes to the development of trainee initiative, as well as the development and improvement of oral speech skills [5, p. 126].

In the educational process, students master a variety of knowledge, skills and abilities. This forces the teacher to use the appropriate variety of methods. To assess the knowledge most often use the methods of oral and written interviews. Conversations, testing, questioning, oral interviews are organized in such a way as to induce either all involved in the answer - the frontal approach, or individual ones - the individual approach. Consequently, the complex of purposeful learning activities that develop the skills and abilities of speech activity should include both preparatory and developmental exercises. Such exercises require students to make certain intellectual efforts in order to form speech skills in student-athletes. Such situations and exercises confirm the real possibility of mastering English even for a short period of study. We will do everything possible to develop students' interest in foreign languages.

The eminent Russian educator V.A. worked a lot on this problem. Sukhomlinsky. Showing constant attention to culture, speech culture, V.A. Sukhomlinsky wrote that there is one side of the pedagogical 
culture, about which it is impossible to speak without anxiety - this is the teacher's speech culture. The teacher's speech culture is crucially determined by the efficiency of students' mental work in the classroom.

\section{DISCUSSIONS}

The university teacher is simply obliged to develop the habit of students to monitor their speech, improve their speech culture. Negligence with respect to oral speech by the teacher is unacceptable. The most important task of a teacher is to teach students to speak in different ways, depending on the purpose of the statement and the addressee, that is, to teach how to use speech according to circumstances.

Speech skills ensure the effectiveness of educational technology. Speech cultures in general and pedagogical eloquence in particular are indicators of the level of pedagogical professionalism. Speech culture and pedagogical professionalism can be analyzed through activity and communication. In this case, through pedagogical activity and pedagogical communication.

To improve the students' speech culture, the teacher must possess a system of speech skills, on which the success of speech training depends.

\section{CONCLUSIONS}

To fully communicate, the teacher must have a number of skills. First, to be able to quickly and correctly navigate the conditions of communication. Secondly, to be able to choose the right content of the act of communication. Thirdly, find adequate means to transmit this content. And fourth, be able to provide feedback. If any of the links in the act of communication is broken, then the speaker will not be able to achieve the expected results of communication - it will be ineffective. Speech is the creative function of the human psyche, reflecting in the speech statement every new situation arising in the communicative process. In it, the influence of social factors is especially vivid and manifold. Human speech behavior is caused not only by constant social characteristics, but also situational characteristics, reflecting changes in social roles and causing speech switching.

\section{REFERENCES}

1. Nelyubin L.L. Linguistic-stylistics of modern English: Textbook. - 4th edition, trans. and add. M .: Flint: Science, 2007.

2. Winter I.A. Psychological aspects of learning to speak in a foreign language. - M., 1985. - $145 \mathrm{p}$.

3. Nelyubin L.L. Linguistic-stylistics of modern English: Textbook. - 4th edition, trans. and add. M .: Flint: Science, 2007.

4. Kryuchkova L.S. Practical methods of teaching Russian as a foreign language / L.S. Kryuchkova, N.V. Moschinskaya // Russian as a foreign language: Textbook. - 3rd ed. - M .: FLINT: Science, 2012.

5. Nevzorov A.M., Nikolaev. A Handbook for the Development of Speech. - Tashkent, Ukituvchi, 1992.

6. Çağlayan, E., Şak, N., Karymshakov, K., Çaglayan, E., \& Sak, N. (2012). RELATIONSHIP BETWEEN TOURISM AND ECONOMIC GROWTH: A PANEL GRANGER CAUSALITY APPROACH. Asian Economic and Financial Review, 2(5), 591-602.

7. Festel, Gunter (Swiss Federal Institute of Technology, Department of Management, Technology and Economics / Technical University Berlin, Faculty of Economics and Management, Berlin, G., Nardo, Mikko (Swiss Federal Institute of Technology, Department of Management, T. and E., \& Simmen, Timo (Swiss Federal Institute of Technology, Department of Management, T. and E. (2014). Research paper Outsourcing of Pharmaceutical Manufacturing - A Strategic Partner Selection Process. Journal of Business Chemistry, 11(3), 117-132. https://doi.org/10.1080/00219266.2013.837405

8. Journal, M., \& Journal, M. (1995). Shaker Zahra Georgia State Univeisity Gregory. G. Dess Univeisity of Kentucky. Business, 10-13.

9. Willson, G. (2011). Research themes for tourism. E-Review of Tourism Research. https://doi.org/10.1080/1743873X.2011.601882 